\title{
Dynamics of communicable diseases mortality in South Africa, 2000-20I3
}

\author{
E. $O$ Udjo \\ Bureau of Market Research, University of South Africa \\ Pretoria, South Africa \\ bororue@yahoo.com; udjoe@unisa.ac.za
}

\begin{abstract}
Context/Background: Communicable diseases dominate non-communicable diseases as causes of death in Africa. However, knowledge about their dynamics in the region is limited. This study examines the dynamics of communicable diseases mortality during the period 2000-20I 3 in South Africa.

Data Sources and Methods: The data consisted of death records from South Africa's death registration system utilizing International Classification of Diseases Revision 10 codes. The estimates included computing age standardized death rates and logistic regression of factors associated with communicable diseases deaths.

Results: Communicable diseases' deaths contributed at least a third to total deaths in South Africa in 2013.

Conclusion: Despite the roll out of free anti-retroviral therapy in public health facilities since 2004 and contrary to what some other researchers have argued, death rates from HIV/AIDS as underlying cause of death, increased during the period 2000-20I3.
\end{abstract}

Keywords: Communicable diseases, Epidemiological transition, HIV/AIDS, Mortality, South Africa, Standardized death rates

\section{Introduction}

\section{Statement of the problem}

Communicable diseases mortality is a global phenomenon. Although mortality patterns have changed since the 1990s, with chronic noncommunicable diseases exceeding communicable, maternal, and perinatal causes (Capilheira, 2008) communicable diseases still contribute substantially to total mortality globally. Of the $\mathbf{5 2 . 8}$ million deaths globally in 2010, communicable diseases together with maternal, neonatal and nutritional causes, accounted for about $24.9 \%$ of the deaths, down from I5.9 million (34.1\%) of 46.5 million deaths in 1990 (Lozano, 2012). Communicable diseases have a greater impact in developing nations (Mainali, 2006).

It is only in Africa of all the regions in the world that communicable diseases dominate noncommunicable diseases as causes of death (Beaglehole, 2003). In spite of the global improvements, communicable diseases, together with maternal, nutritional and new-born diseases still dominate total mortality in sub-Saharan Africa (Beaglehole, 2003). Although the relative burdens of diarrhea and lower respiratory diseases have declined, communicable diseases, new-born, nutritional, and maternal causes such as diarrhea, lower respiratory infections and protein-energy malnutrition remain the top drivers of health loss in most sub-Saharan countries (The World Bank, 2013). Furthermore, communicable diseases such as HIV/AIDS and malaria accounted for a larger proportion of disability in sub-Saharan Africa than in the world as a whole in 2010 (The World Bank, 2013). Infectious diseases still cause the majority $(69 \%)$ of deaths in sub-Saharan Africa (Young et al., 2010).

A number of studies have quantified the levels and trend in causes of death globally. The 2013 global burden of disease study is an example (see the Lancet, 20I5). Although, communicable diseases deaths were included in the study, the analysis on Africa was based on limited data from surveys, censuses, vital registration, verbal autopsies and household recall of deaths. Specifically, the cause of death data on Africa ranged from no data (Somalia and Equatorial Guinea) to 35 or more site years of vital registration and verbal autopsy site years. A site year was defined in the study as data for a specific geographical location which implies data could for example be available for a specific province within a country but not necessarily for the entire country. Furthermore, although the study provided estimates of completeness in vital registration in the data points $-85 \%$ or more complete for $77 \%$ of the data points, $70-84 \%$ complete for the $17 \%$ of the data points, and less than $70 \%$ complete for $6 \%$ of the data 
points - it did not indicate into which of these three groups African countries fell.

The data used in the previous global burden of disease study by Wang et al. in 2010 (see The Lancet, 2012) were even more limited. For example of all the African countries included in the study, data points from vital registration data could only be produced for Madagascar, South Africa, Zimbabwe, Cape Verde and Sao Tome and Principe. Thus our knowledge of the dynamics of communicable diseases in sub-Saharan Africa is limited.

Beside Mauritius, South Africa is the only country in the region with a long history of death registration dating back to the early 20th century and where coverage of registration of deaths exceeds $80 \%$ nationally according to estimates. Focus on communicable diseases mortality in South Africa has been mainly on HIV/AIDS-related mortality and recently, on tuberculosis mortality. A number of reports and papers have emanated from South Africa's Medical Council's Burden of Diseases Research Unit. However, few of these studies examined communicable diseases, some with limited focus. Bradshaw et al.'s (2016) study focused specifically on HIV/AIDS. Furthermore, the conclusion - that there was a reversal of HIV/AIDS mortality after 2006 - from Pillay-van Wyk et al.'s (2016) study using data from death notification is contentious.

Although Statistics South Africa (Stats SA) periodically publishes mortality and causes of death, each report largely focuses on a specific year and the scope of the reports is broad. Additionally, although the reports provide the number of registered deaths for each year since 1997, it is difficult to glean from the reports whether or not progress is being made in mortality reduction. It is not possible to make such judgments from absolute numbers of registered deaths. For example, in the summary and concluding remarks in the 2013 report, Stats SA (2014) noted that "deaths continue to decline in the country as observed from 2007 in registered deaths processed by Stats SA, following a persistent increase from 1997 to 2006. In 2013, the total number of deaths processed by Stats SA decreased by $6.5 \%$ from a total of $49 \mathrm{I}, 100$ deaths that occurred in 20I2". It is difficult to deduce from such a statement whether or not such dynamics implies mortality decline in the country or data quality problem.

\section{Objectives}

Against this background, the purpose of this study is to extend existing knowledge on communicable diseases mortality to an African country by examining the dynamics of communicable diseases deaths in South Africa during the period 2000-2013. The specific objectives are: (I) Examine dynamics in standardized mortality ratios due to communicable diseases during the period 2000 to 2013 nationally with year 2000 as the base year for comparison; (2) Examine dynamics in standardized mortality ratios in broad categories of communicable diseases nationally during the period 2000 to 2013 with year 2000 as the base year for comparison; and (3) Examine factors contributing to communicable diseases deaths and sub-group differences. Though not a primary objective, provincial numbers are also presented as a means of evaluating the quality of the data. The results from objective (I) and (2) should provide objective basis for assessing whether or not progress has been made in reducing mortality in the country since 2000.

A study of this nature is useful to the public and private sectors. In fact, mortality by cause are a key to modifying the health system (Alam et al., 20I0). Furthermore, information on mortality is indispensable in actuaries, for example, in determining insurance premiums in life policies. Information on mortality also provides insights about the quality of the environment and poverty as some communicable diseases are environmental and poverty-related.

\section{Contextualising communicable diseases mortality}

The shift in dominance of communicable diseases relative to non-communicable diseases is often explained using the theory of the epidemiological transition (Ghaffar et al., 2004; Omran, 2005; Yang et al., 2008; Alam et al., 20I0; Dalal, 20II). The theory focuses on shifts in the patterns of diseases and mortality. It posits that during the transition, there is a shift in mortality patterns and diseases whereby pandemics of infections are gradually displaced by degenerative and man-made diseases as the primary cause of death (Omran, 2005). During this stage, average life expectancy increases and fertility becomes the primary driver of population growth (Omran, 2005).

The theory is derived from the demographic transition theory (Harper and Armelagos, 20I0). This theory emphasizes the shift from high mortality and fertility in the pre-transition period to low fertility and mortality in the transition period (Weeks, 1999), first proposed by Thompson (Thompson, 1929) cited in Harper and Armelagos (2010) and expanded by Notestestein (Notestein, 1945) cited in Harper and Armelagos (2010). Population ageing accompanies demographic transition resulting in a shift from communicable diseases to non-communicable diseases as the dominant causes of death. Although most evidence of the epidemiological transition comes from industrialized countries (Gu et al., 2009), 
while industrialized countries have successfully undergone the epidemiological transition, developing countries have not (Sanders et al., 2008).

The epidemiological transition is not a unidirectional process as was first thought but a complex continuous and dynamic process with some diseases disappearing and others re-emerging (Wahdan, 1996), such as the emergence of HIV and the re-emergence of malaria and tuberculosis driven by newly developed drug resistance (Sanders et al., 2008). While the emergence and re-emergence of infectious diseases challenges one to re-think the epidemiological transition theory (Rumakom et al., 2002), the theory has influenced thinking about the evolution of health in different societies and the response of the health system to these changes (Salomon and Murray, 2004). One of such thinking is the Mosley and Chen's framework for the study of child survival which can be adapted for the study of mortality in general. The framework involves a redefinition of cause of death (Mosley, 1984, Mosley and Chen, 1984). The framework provides a conceptual bridge linking biological causes of diseases and deaths with proximate determinants, and the associations of socio-economic factors with the proximate determinants as well as their demographic consequences (Mosley, 1984). The dynamics of communicable diseases deaths examined in the first part of this study may be seen as the demographic outcome of communicable diseases while the second part of the study may be seen as gauging the importance of independent variables in communicable diseases deaths in South Africa.

\section{Methods}

\section{Data and limitations}

The study utilized death registrations data for the period 2000-20I 3 from South Africa's Department of Home Affairs processed by Stats SA although the systematic compilation of causes of death information in South Africa began in 1997. The death records prior to 2000 were omitted because completeness of death registration was lower during that period (Udjo, 2006). The most recent available causes of death data at the time of this study were for the period 20I3. The process of coding, compilation and publishing of death records in South Africa may be summarized as follows: It is a legal requirement in South Africa that all deaths and their causes be certified and notified to the Department of Home Affairs. Stats SA obtains the death notification forms from the Department of Home Affairs. It processes the death notification forms using the 10th revision of the International Classification of Diseases (ICD-I0). The underlying causes of death are derived using a software program - Automated Classification of
Medical Entities (Udjo, 20I I). The analysis presented in this study was based on the immediate and underlying causes as processed by Stats SA. A total of $8,509,8 \mid 4$ deaths during the period 1997-2013 were registered.

The limitations of the data include the following. It is well known that in developing countries, especially in sub-Saharan Africa, death registration is either non-existent or does not cover the entire country or not all deaths are registered or are registered late. Estimates of death rates using death registration data in these circumstances are biased downward. Miss-classification of causes of death may be another limitation using death registration data.

In the context of South Africa, death registration has been operational since 1910 though in its initial phase, did not cover the entire country (Khalifani et al., 2005). Presently, it is a requirement by law that one obtains a burial order which includes a death certificate before burying a deceased. Although there may not be complete compliance in rural areas, completeness of death registration should be close to $100 \%$. In one study, completeness of death registration was over $90 \%$ in the early 2000 s in South Africa (Groenwald et al., 2005). In another study, estimated death registration increased for females from about $74 \%$ in 1997 to about $84 \%$ in 2006 while for males, it increased from about $84 \%$ in 1997 to about 92\% in 2006 (Udjo, 2006). These estimates indicate high coverage of death registration though not $100 \%$ complete in South Africa. Administrative lapses in the processing of the death notification forms can artificially add to incompleteness if all the death notification forms were not processed. Despite these limitations, this study provides insight into the dynamics of communicable diseases mortality in South Africa.

\section{Defining communicable diseases}

Communicable diseases are pathogens that are transmitted directly or indirectly from one person to another usually involving an infectious organism (McKinney, 20I2). The two broad categories according to the ICD-I0 classification are: (I) Infectious and parasitic diseases, and (2) Respiratory infections. The broad sub-groups in these categories are: Infectious and parasitic diseases: tuberculosis, sexually transmitted excluding HIV/AIDS, HIV/AIDS, diarrhea, childhood-cluster, meningitis, hepatitis, malaria, tropical-cluster, leprosy, dengue, Japanese, encephalitis, trachoma, intestinal nematode infections; Respiratory infections: lower respiratory infections, upper respiratory infections, otitis media. 


\section{Computing the standardized mortality ratios}

Comparing the number of registered deaths or crude death rates from one year to another does not give an indication of whether or not progress has been made in reducing mortality in the population. This is because absolute population size may be changing and crude death rates do not take into account changes in age structure over time. Also, age structure is not uniform across sub-groups in a population in the same period. Therefore, it is necessary when using crude death rates to examine dynamics in mortality over time and between subgroups, to control for differences in age structure. In order to examine progress in the reduction of mortality over time, it is necessary to compare yearon-year rates with a base rate. To illustrate this point using the Millennium Development Goals (MDG) as an example, Goal 4 specified: reduce by two thirds, between 1990 and 2015, the under-five mortality rate (United Nations, 2003). This meant that underfive mortality rates in 1991 - 2015 had to be compared with the rate for 1990 in order to determine progress in achieving Goal 4.

In the context of this study, one approach in examining dynamics in communicable diseases mortality is direct or indirect standardization. This study utilized indirect standardization and the technique is described in Udjo (20II), Udjo \& Lalthapersad-Pillay (20|4). In the present study, it consisted of the following steps: (I) a standard set of age specific death rates from communicable diseases as immediate or underlying cause was defined. The standard population was taken as 2000 for the reason note above. The age groupings were $0-14,15-49,50$ 59,60 years and over. Both sexes were combined in the analysis due to small numbers. (2) Age specific communicable diseases death rates using the above age groupings for the year $\mathbf{2 0 0 0}$ were computed and these taken as the standard death rates. (3) The expected numbers of cases of communicable diseases deaths for each other year (200I, 2002... 20I3 i.e. index populations) were computed as the product of the standard communicable diseases death rates and observed communicable diseases deaths rates for the index population. (4) Standardized mortality ratios (SMR) were computed from (I) and (2) as:

$\mathrm{SMR}=\mathrm{Dc} / \mathrm{Ec}$

where $D c$ is the total number of deaths from communicable diseases observed in the index population, Ec the expected number of deaths from communicable diseases in the index population. (4) Lastly, age standardized crude death rates (ACDR) were computed as:

$A C D R=S M R * C D R s$

$\mathrm{CDRs}=\mathrm{Ds} / \mathrm{Ps}$ where CDRs is the crude death rate from the communicable diseases in the standard population, Ds, the total number of communicable diseases deaths in the standard population and Ps the midyear population in the standard population.

\section{Estimating the denominator in computing the death rates}

Estimates of death rates require that the mid-year population size be known. Three censuses (in 1996, $200 \mathrm{I}$ and 20 I I) have been undertaken in South Africa since the end of apartheid in 1994. Although the census figures are controversial, they constitute the basis for many population estimates or projections in the country, including the present study.

Since the censuses were undertaken in October of the census years, in the present study, the figures were adjusted to mid-year by age group (under I, I$4,5-9,10-14 \ldots 80+)$ using exponential interpolation. For the year 2000 for which census figures were not available, the mid-year population was obtained by exponential interpolation by age group on the 1996 and $200 \mathrm{I}$ census figures. Similarly, exponential interpolation was performed on the 200I and 20II census figures to obtain the estimated age distributions for each of the years during the period 2002-2010. Also, exponential extrapolation was performed on the $200 \mathrm{I}$ and $20 \mathrm{II}$ census figures to obtain the estimated population age distributions for 2012 and 2013. Though performed separately for males and females, the results for both sexes were combined for the age distributions described above due to small numbers in some of the sub-categories of communicable diseases.

Given the controversies in the census figures, it is possible that the mid-year population estimates are biased and estimates utilizing such figures could be biased. Theoretically, if the mid-year estimates were biased upward, the estimated death rates utilizing the mid-year estimates as denominator would be biased downwards. However, in the present study, the bias should not mask trends since the denominator is the same for total deaths and subcategories of deaths. However, provincial comparisons of results would need cautious interpretation since probable bias in the 201I and other census figures may be more marked in some provinces relative to others.

Factors contributing to communicable diseases deaths and sub-group differences

A bi-variate $x 2$ analysis was done to test whether or not there was a relationship between dying of communicable diseases and each characteristic of the deceased. The demographic and socio-economic characteristics available in the 2013 data were sex, 
age, marital status, educational level, province of residence, occupation and industry). Educational level was excluded from the analysis because of the large percentage of missing values (54.7\%). Furthermore, industry in which the deceased worked most of his/her life was also excluded from the analysis because that level of detail was not considered important in the present study. Beside the two excluded variables, the characteristics that were statistically significant at $p<0.05$ were then included in a single multivariate analysis. This approach was also used to assess sub-group differences in the odds of dying from communicable diseases. The multivariate analysis utilized was logistic regression.

A logit model explains the outcome variable $Y_{i}$ taking values 0 or $I$ in terms of subject $i$ in terms of a row vector covariate Xi (Freedman 2009). The logit regression model in the current application may be expressed as:

$\operatorname{Prob}(C D)=I /\left(I+e^{\wedge}\left(-\left(B \_0+B \_I X \_I+B \_(2)\right.\right.\right.$ X_2+B_(3) X_3.... $\left.\left.\left.B_{-}(\mathrm{n}) X_{-}^{-} \mathrm{n}\right)\right)\right)$

(Hosmer and Lemeshaw, 2000) where Prob(CD) is the probability of a person dying of communicable disease (CD), the dependent variable.

$C D=1$ if the immediate or underlying cause of death was $C D$;

$C D=0$ if the immediate or underlying cause of death was not $C D$;

$\mathrm{e}=$ base of the natural logarithm;

$\beta 0=$ constant;

$\beta \mid . . n=$ estimated coefficients corresponding to the covariates $X I \ldots X n$, the control variables where:

$\mathrm{XI}=$ Sex: $\mathrm{I}=$ male, $0=$ female (reference category);

$\mathrm{X} 2$ = Age group (Indicator variable with three categories): 0-14 years, 15-64, 65 years and over. Category was coded I if age group was 0-I4, 15-64 (reference group) years or 65 years and over, or 0 otherwise.
X3 = Current marital status (three categories): Never married, Ever married, Below marriage age. Category was coded I if current marital status was never married (reference category), ever married or below marriage age, or 0 otherwise.

X4 = Province of residence (nine categories): Western Cape, Eastern Cape, Northern Cape, Free State, KwaZulu-Natal, North West, Gauteng, Mpumalanga, Limpopo. Each category was coded I if the province of residence of the deceased was any of the above listed or 0 otherwise. The reference category was the Free State.

X5 = Occupation ( 10 categories): Unspecified not economically active; Legislators, senior officials and managers; Professionals, technicians and associate professionals; Clerks; Service workers, shop and market sales; Skilled agriculture and fishery workers; Craft and related trade workers; Plant and machine operators; Elementary occupations. Each category was coded I if the occupation of the deceased was any of the above listed or 0 otherwise. The reference category was Elementary occupations. The logistic regression model was applied to the causes of death data for 2013 (the most recent data available at the time of the study).

\section{Results}

Absolute numbers of total registered deaths and registered deaths from communicable diseases, 2000-20I3

The absolute numbers of registered deaths during the period 2000-2013 are shown in Figure I. The graph suggests that the number of registered deaths increased during the period 2000-2006 and decreased thereafter. The trend after 2006 is rather odd because South Africa's population is increasing and ageing gradually. The population of South Africa increased from 40.6 million in 1996 to 51.8 million in 20II (Stats SA, 1998, 20I2). 
Figure I: Absolute numbers of total registered deaths and communicable diseases deaths, 2000-20I3

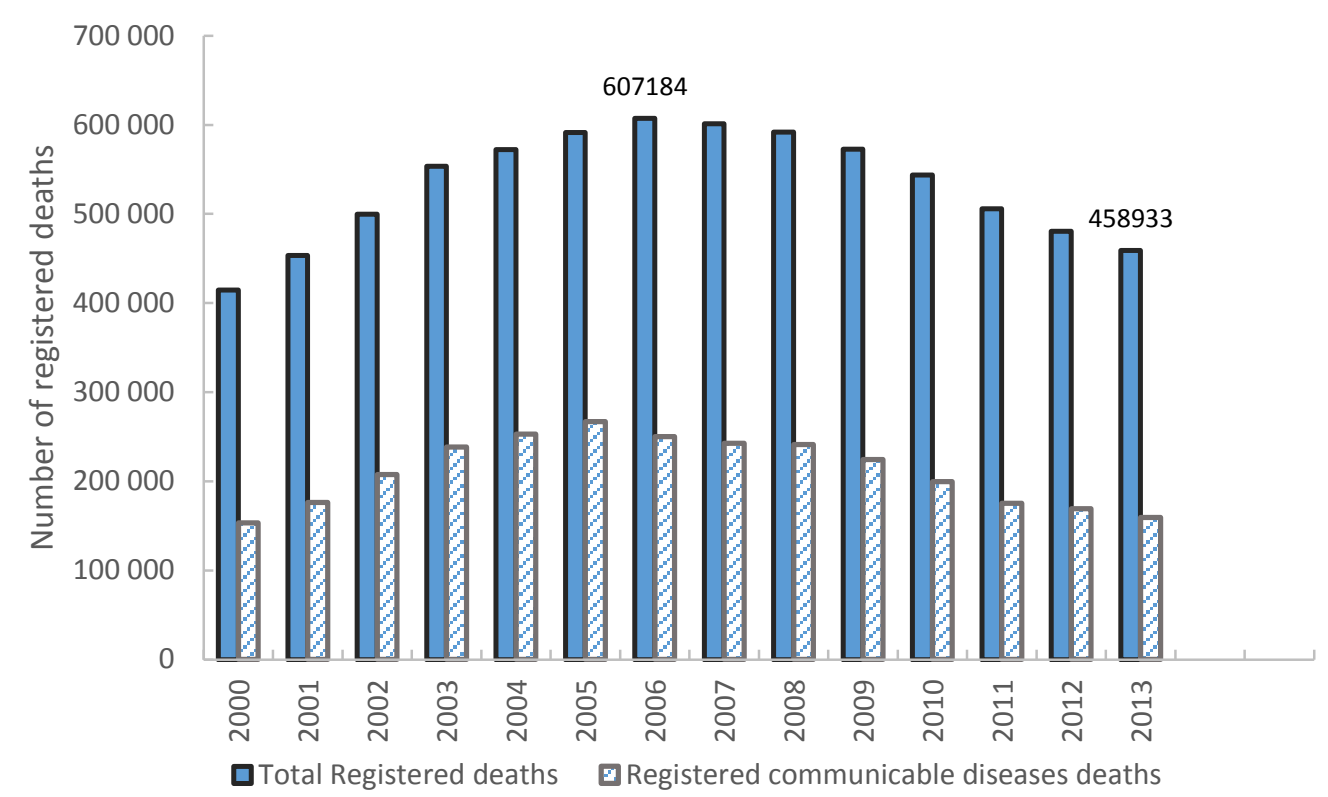

Source: Computed from Causes of Death Data

Computations from the 1996 and 2011 census data indicate that the percentage of the population aged 60 years and above increased slightly from $7 \%$ in 1996 to $8 \%$ in 2011 . In view of these, the absolute number of deaths in the population should increase with time even if some people who are HIV positive are living longer. As a means of evaluating the national figures, the trends in the provincial figures are shown in Figure 2. The absolute number of deaths in the Northern Cape, Western Cape and Limpopo as seen in Figure 2 are consistent with this reasoning. This suggests that the quality of the data on registered deaths in KwaZulu-Natal, Eastern Cape and Gauteng largely responsible for the pattern in Figure I, may be questionable.

Figure 2: Total Numbers of Registered Deaths by Province, 2000-2013

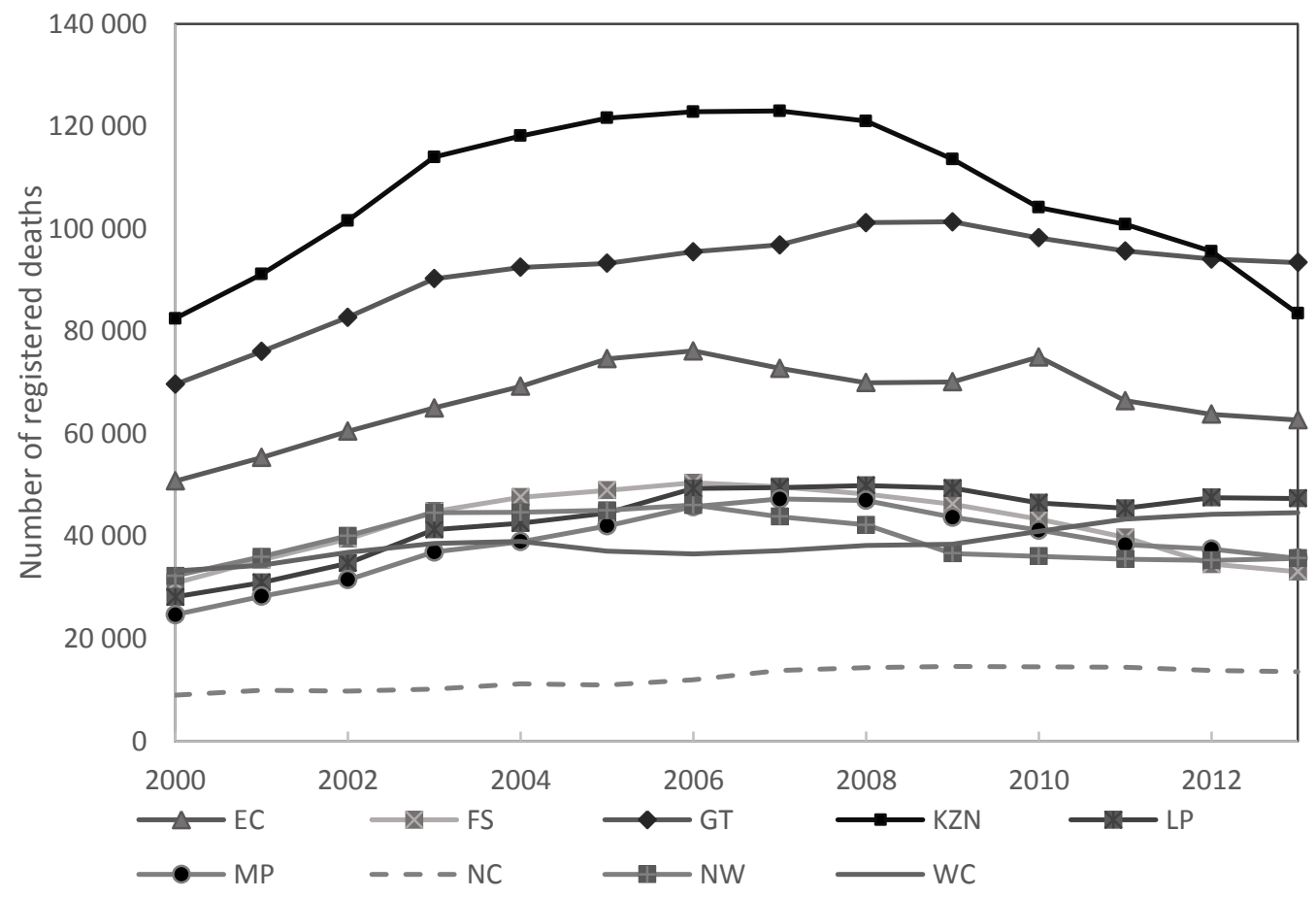


$\mathrm{EC}=$ Eastern Cape, $\mathrm{FS}=$ Free State, GT $=$ Gauteng, $\mathrm{KZN}=$ KwaZulu-Natal, LP $=$ Limpopo, MP = Mpumalanga, $\mathrm{NC}=$ Northern Cape, NW $=$ North West, $\mathrm{WC}=$ Western Cape

Source: Computed from Causes of Death Data

Contribution of communicable diseases to total deaths

The results of the analysis indicate that communicable diseases deaths contributed about $31 \%$ of the total deaths in South Africa in 2000 peaking at $45 \%$ in 2005. The contribution to total deaths appeared to have declined since 2006 (graph not shown). However, as of 2013, the relative prominence of communicable diseases deaths to total deaths (34\%) was still higher than the relative prominence in 2000.

Standardised mortality ratios from communicable diseases

Figure 3 suggests that standardised crude death rate from communicable diseases was about 1.8 times higher in 2006 than the level in 2000. Although there was apparent decline in crude death rates in communicable diseases after 2006, the standardised mortality ratios (SMR) indicate that crude death rates from communicable diseases were higher each year up to 2012 than the level in 2000. While the crude death rate from communicable diseases was seemingly about $80 \%$ higher in 2006 than the level in 2000 , it was about $11 \%$ higher in 2012 than the level in 2000. It appeared there was a sharp spike in death rate from communicable diseases in 2006 (507 per 100,000 population) compared to the corresponding level in 2000 (289 per 100,000 population). Only in 2013 did the standardised crude death rate $(282$ per 100,000 population) fall below the level in 2000 as seen in the SMR of 0.98 in Figure 3.

Figure 3: Standardised Mortality Ratios from Communicable Diseases, 2000-20I3

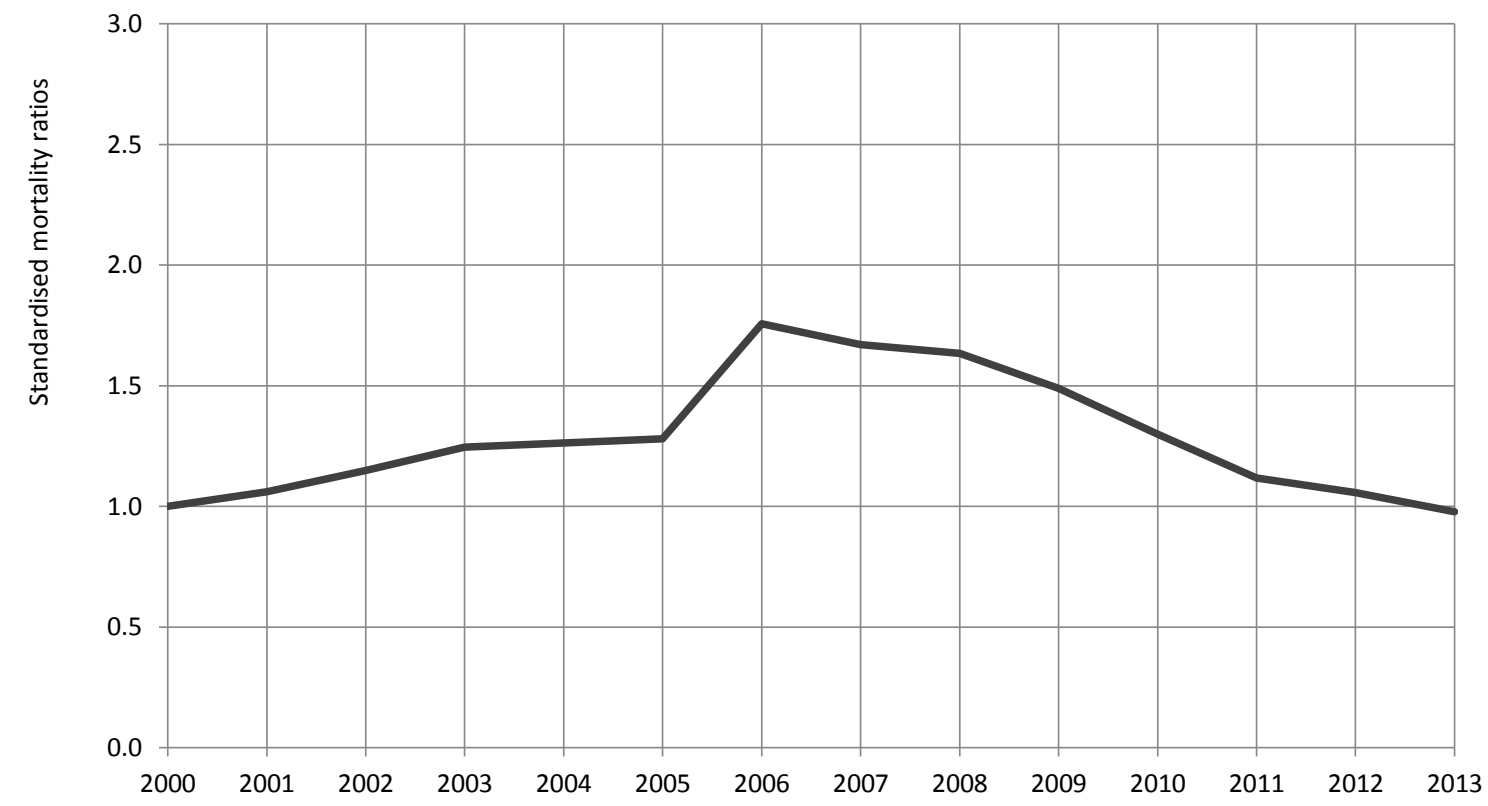

Source: Computed from Causes of Death Data

Profile of communicable diseases deaths in South Africa

The tabulation of the profile of communicable diseases deaths in South Africa for the year 2013 (Table not shown) indicated that certain communicable diseases deaths are very rare or nonexistent in South Africa. These include tropical diseases cluster (trypanosomiasis, chaga diseases, schistosomiasis, leishmaniasis, lymphatic filariasis, onchocerchiasis), leprosy, dengue, Japanese encephalitis, trachoma, intestinal nematodes and otitis media. These were therefore excluded in subsequent analysis.

Standardized death rates in selected sub-groups of communicable diseases, 2000-20I3

Figure 4 suggests that although death rates from certain sub-groups of communicable diseases deaths may have declined in comparison with the rates in 2000, tuberculosis, lower respiratory infections 
(including influenza, pneumonia, bronchitis), and diarrhea remain the top three communicable diseases death rates. Furthermore, despite anti-retroviral treatment introduced in public sector clinics and hospitals in 2004 (Gonzalez, 20/4), death rate from HIV/AIDS as underlying cause of death continued to increase such that in 2013, the crude death rate from HIV/AIDS as underlying cause of death in 2013 (43 per 100,000 population) was about I.8 times higher (Figure 5) than the corresponding level in 2000 (24 per 100,000 population). Furthermore, Figure 5 indicates that of all the sub-groups of communicable diseases, its only sexually transmitted diseases excluding AIDS and malaria that the death rates were consistently below the corresponding 2000 levels.

Figure 4: Trends in Standardised Crude Death Rates in Selected Sub-groups of Communicable Diseases, 2000-20I3.

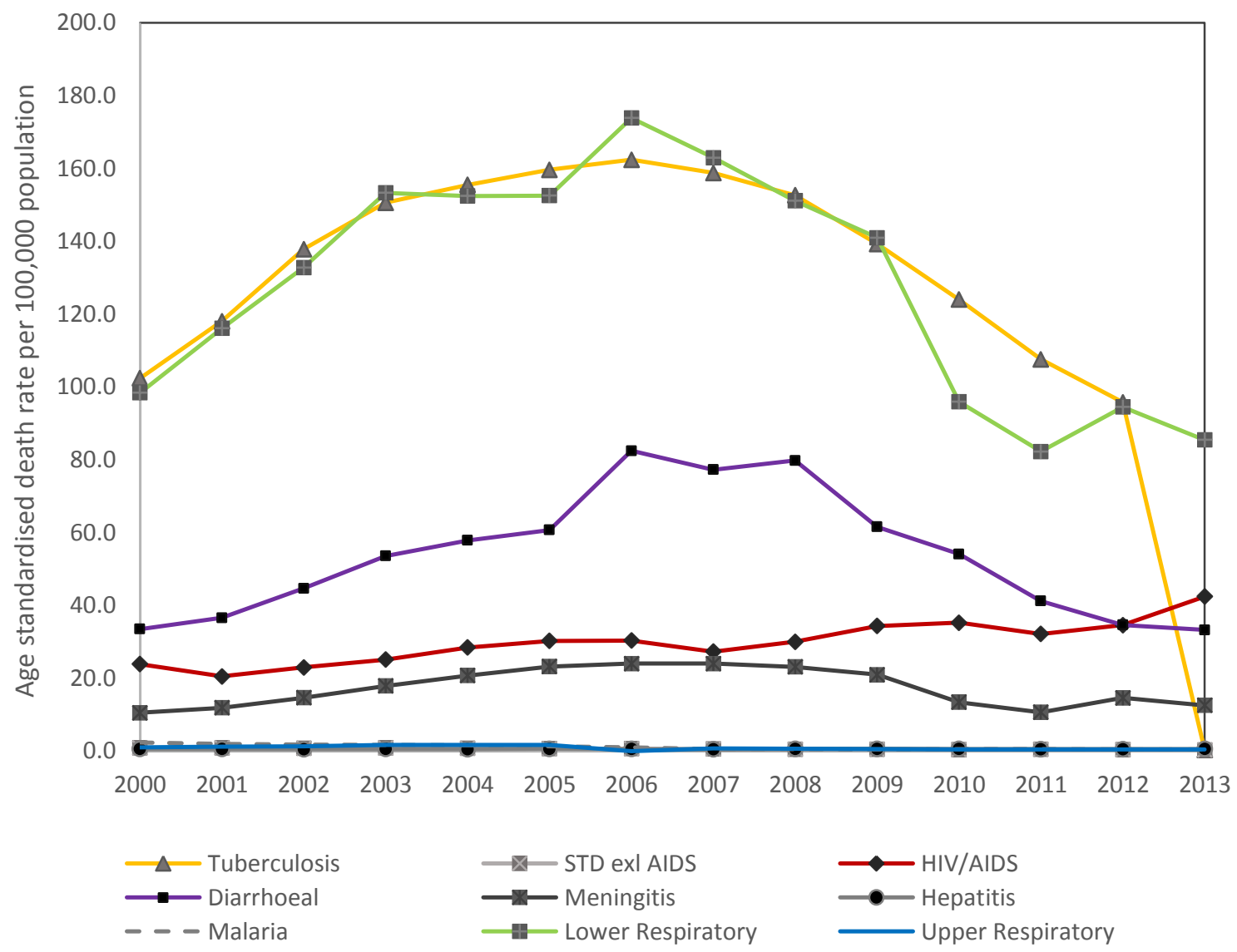

Source: Computed from Causes of Death Data, 2000-20I3 
Figure 5: Standardised Mortality Ratios, in Selected Sub-groups of Communicable Diseases, 2000-20I3.

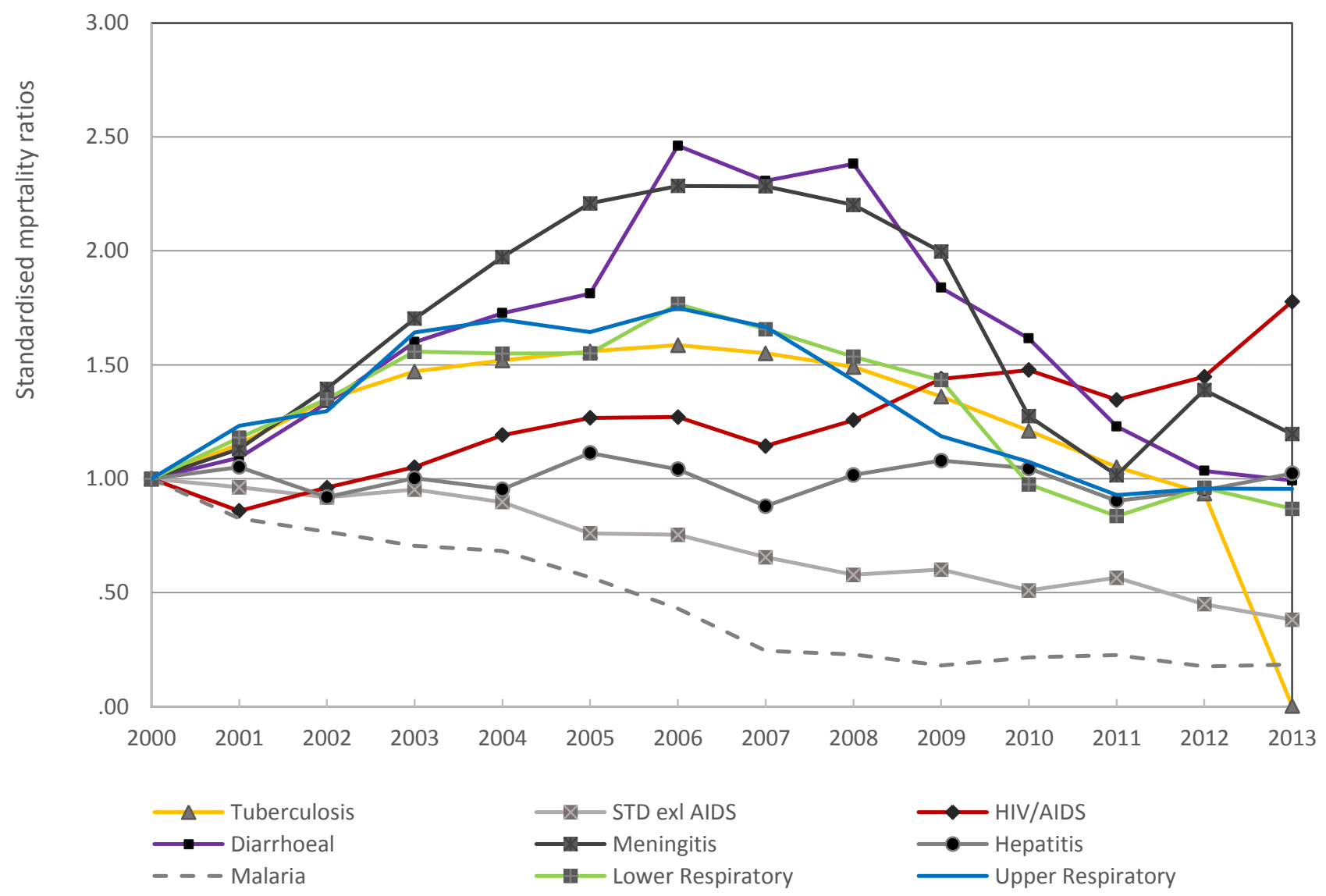

Source: Computed from Causes of Death Data, 2000-2013

Factors contribution to communicable diseases deaths and sub-group differences

The Wald test for each of the coefficients of the factors in the logistic regression model indicate that the sex of the deceased, age, marital status, occupation and province of residence contributed (denoted by asterisks in Table I) to the probability of dying from communicable diseases deaths ( $p<$ 0.000) in 2013. As seen in Table I, males had significantly lower odds of dying from communicable diseases than females in 2013 controlling for age, marital status, occupation and province of residence $(p<0.000)$. Persons aged 65 years and over in 2013 had significantly lower odds of dying from communicable diseases than persons aged 15-64 years during the same period controlling for the other factors. The results also indicate that persons who were in elementary occupations had higher odds of dying from communicable disease than persons in each of the other occupations except plant and machine operators controlling for the other factors. Lastly, persons whose province of residence was the Free State had significantly lower odds of dying of communicable diseases than persons whose province of residence was any other province except the Eastern Cape in 2013 controlling for the other factors $(p<0.000)$. Although the results indicated that the sex of the deceased, age, marital status, educational level, occupation and province of residence contributed significantly to communicable diseases deaths, the low value of the Nagelkerke R2 - 0.095 - seen in Table I suggests the effect of these factors is small. This is probably because these are indirect determinants of mortality. This indicates that other factors (direct determinants which were not available in the data) not considered in the model presented were more contributory to communicable diseases deaths. 
Table I: Logistic regression of communicable diseases deaths by demographic and socio-economic factors in 2013

\begin{tabular}{|c|c|c|}
\hline \multirow[b]{2}{*}{ Variable } & \multicolumn{2}{|l|}{ Logistic Regression } \\
\hline & Coefficient & Odds Ratio \\
\hline \multicolumn{3}{|l|}{ Sex } \\
\hline Male & $-0.145(0.008)^{* *}$ & 0.865 \\
\hline \multicolumn{3}{|l|}{ Female (RF) } \\
\hline \multicolumn{3}{|l|}{ Age Group } \\
\hline \multicolumn{3}{|l|}{ I5-64 (RF) } \\
\hline $65+$ & $-0.900(0.009)^{* *}$ & 0.407 \\
\hline \multicolumn{3}{|l|}{ Marital Status } \\
\hline Ever married & $-0.420(0.008)^{* * *}$ & 0.657 \\
\hline \multicolumn{3}{|l|}{ Never married (RF) } \\
\hline \multicolumn{3}{|l|}{ Occupation } \\
\hline Legislators, senior officials \& managers & $-0.450(0.055)^{* * *}$ & 0.637 \\
\hline Professionals & $-0.366(0.030)^{* * *}$ & 0.693 \\
\hline Technicians \& associate professionals & $-0.328(0.05 I)^{* * *}$ & 0.720 \\
\hline Clerks & $-0.255(0.047)^{* * *}$ & 0.775 \\
\hline Service workers, shop \& market sales & $-0.068(0.027)^{*}$ & 0.934 \\
\hline Skilled agriculture \& fishery workers & $-0.051(0.040)$ & 0.951 \\
\hline Craft \& related trade workers & $-0.102(0.029)^{* * *}$ & 0.903 \\
\hline Plant \& machine operators & $0.079(0.026)^{* *}$ & 1.082 \\
\hline \multicolumn{3}{|l|}{ Elementary occupations (RF) } \\
\hline \multicolumn{3}{|l|}{ Province of Residence } \\
\hline Eastern Cape & $-0.284(0.017)^{* * *}$ & 0.753 \\
\hline Gauteng & $0.313(0.013)^{* * *}$ & 1.367 \\
\hline KwaZulu-Natal & $0.060(0.024)^{* *}$ & 1.062 \\
\hline Limpopo & $0.023(0.013)$ & 1.023 \\
\hline Mpumalanga & $0.146(0.017)^{* * *}$ & 1.157 \\
\hline North West & $0.235(0.017)^{* * *}$ & 1.265 \\
\hline Northern Cape & $0.467(0.016)^{* * *}$ & 1.596 \\
\hline Western Cape & $0.394(0.015)^{* *}$ & 1.482 \\
\hline \multicolumn{3}{|l|}{ Free State (RF) } \\
\hline Constant & $-246(0.011)$ & \\
\hline Nagelkerk $R^{2}$ & 0.095 & \\
\hline
\end{tabular}

$\mathrm{RF}=$ Reference category, standard error in parenthesis ** statistically significant, $p<0.00$.

* Statistically significant, $p<0.05$.

Source: Computed from Statistics South Africa's death records data.

\section{Discussion and conclusion}

This study set out to examine the dynamics of communicable diseases in South Africa. The analysis suggests that there are quality issues in the data. Given that: (I) In theory, one cannot bury a deceased without a death certificate in South Africa since all deaths need to be registered by law; (2) Recognizing that there may be some non-compliance with death registration in rural areas; (3) Burial takes place within I-2 weeks after death in South Africa; (4) South Africa's population is growing and ageing gradually; the total number of registered deaths should increase with time. Therefore, the decline in the absolute number of registered deaths observed in the data during the period 2006-2013 may not be attributed wholly to incomplete death registration 
but probably largely due to unavailability of a large number of the death records for processing. Demographic modelling by this author for example estimated a total 621,469 in 2013 deaths whereas the officially published figures gave 458,933 for the same period i.e. an estimated shortfall of 162,536 deaths for the period 2013 in the published figures.

In other words, the death records actually processed were probably a smaller percentage of the actual number of the notification forms completed by relatives of the deceased. Thus, the apparent downward decline in the absolute number of registered deaths during the period 2006 and 2013 may be due to administrative lapses rather than failure to register deaths. However, this does not rule out completely, failure to register some of the deaths. The issue of late registration cannot be the reason for the apparent downward decline in the absolute number of registered deaths during the period 2006 and 2013 for the reasons explained above. Another argument against late registration is that this author cannot come up with any logical reason why late registration would have been more marked for the period 2006 and 2013 compared to the period 2000 and 2005.

It was noted above that misclassification of causes of death may be a limitation in using vital registration data. Misclassification of causes of death is not confined to specific diseases but may affect all causes even in settings where vital registration systems are well developed. To illustrate the point, consider the following examples. In a CDC editorial (1986), it was reported that during the period $1977-1984$ in Washington State, $53 \%$ of maternal deaths were originally misclassified as non-maternal. Rampatige et al.'s (20/3) study found that there were major misclassification errors in registered deaths due to vascular diseases and diabetes mellitus in Sri-Lanka. Khosravi et al.'s study (2008) noted that $56 \%$ of vague or ill define causes of death in the Republic of Iran could be reclassified to ischaemic heart diseases and cerebrovascular diseases. Misclassification may be more marked in certain specific causes of death if there is stigma attached to the specific cause in a society such as HIV/AIDS.

Several studies have attempted to quantify the magnitude of misclassifications of causes of death. However, due to limited availability of pathological autopsies as "gold standard" reference diagnoses (Khosravi et al., 2008), the exact magnitude of misclassification of causes of death in vital registration systems cannot be ascertained with absolute certainty. Thus, misclassification of causes of death may continue to be a limitation in using vital registration data.
Despite the above limitations, it appeared from the results of this study that the contribution of communicable diseases deaths to total deaths in South Africa increased during the period $2000-2005$ but seemingly declined during the period 2006 2013. Despite the decline, communicable diseases still contribute at least a third of the total deaths in South Africa.

Of particular note in this study is the dynamics in HIV/AIDS-related deaths. According to Pillay-van Wyk (2016), there was a reversal in HIV/AIDS mortality after 2005 in South Africa and that the "marked decline in HIV/AIDS mortality since 2006 ... can be attributed to the intensified antiretroviral rollout of adults since 2005" (Pillay-van Wyk, 2016: 65I). The current study found no evidence of such trend in HIV/AIDS mortality. The opposite was the case: death rate from HIV/AIDS as an underlying cause of death increased during the period 20002013 despite the rollout of free anti-retroviral therapy in public health facilities since 2004 .

The logistic regression analysis suggests that although demographic and socio-economic factors contributed significantly to communicable diseases deaths in 2013, their effect was quite small. This suggests that other factors may also be important and require further investigation. Unfortunately, the demographic and socio-economic characteristics of the deceased available in the causes of death data are presently very limited. Stats SA should consider the inclusion of additional variables in the data-set. Alternatively, the organization may consider processing the causes of death data in a manner that the data can be linked to other official data-sets that provide household level information. This would make it possible to explore the contribution of other factors to communicable diseases deaths as a means of designing and informing strategies in reducing communicable diseases deaths in South Africa.

\section{Acknowledgement}

The author wishes to thank Stats SA for providing access to their data as well as African Population Studies' anonymous reviewers for their helpful comments and suggestions on the previous version of this article. The views expressed in this study are, however, those of the author.

\section{References}

ALAM, N., CHOWDURY, H.R., BHUIYAN, M.A., \& STREATFIELD, P.K. 20I0. Causes of death of adults and elderly and health care-seeking before death in rural Bangladesh. Journal of Health, Population and Nutrition, 28, 520-528.

BEAGLEHOLE, R., \& YACH, D. 2003. Globalisation and the prevention and control of non- 
communicable diseases: the neglected chronic diseases of adults. The LANCET, 362, 903-908.

BRADSHAW, D., MSEMBURI, W., DORRINGTON, R.E., PILLAY-VAN WYK, V., et al. 2016. HIV/AIDS in South Africa - how many people died from the disease between 1997 and 20I0. AIDS 30(5), 77I778.

CAPILHEIRA, M.F., SANTOS, I.S., AZEVEDO JR. M.R., \& REICHERT, F.F. 2008. Risk factors for chronic non-communicable diseases and the CARMEN initiative: a population-based study in South of Brazil. Cadernos de Saude Publica, 24, I-5.

CDC. (1986). Misclassification of maternal deaths Washington State. CDC Weekly, 35(39): 62I-623.

DALAL, S., BEUNZA, J.S., VOLMINK, J., et al. 201 I. "Non-communicable diseases in sub-Saharan Africa: what we know". International Journal of Epidemiology, 40, 885-90I.

GHAFFAR, A., REDDY, K.S., \& SINGHI, M. 2004. Burden of non-communicable diseases in South Asia. British Medical Journal, 328: 807.

GROENWALD, P., NANNA, N., BOURNE, D., LAUBSCHER, R., \& BRADSHAW, D. 2005. Identifying deaths from AIDS in South Africa. AIDS, 19, 193-20I.

GONZALEZ, L.P. 20I4. South Africa celebrates 10 years of free HIV treatment. Health-E News. (Online) Available: https://www.healthe.org.za/20 |4/04/04/south-africa-celebrates-tenyears-free-hiv-treatment/Accessed 19 January 2017.

GU. D., DUPRE, M.E., WARNER, D.F., \& ZENG, Y. 2009. Changing health status and health expectancies among older adults in China: gender differences from 1992 to 2002. Social Science and Medicine, 68, I70-I79.

HARPER, K., \& ARMELAGOS, G. 20I0. "The changing disease-scape in the third epidemiological transition". International Journal of Environmental Research and Public Health, 7, 675-697.

HOSMER, D.W., \& LEMESHOW, S., 2000. Applied logistic regression. New York: John Wiley and Sons.

KHALIFANI, A.K., ZUBERI, T., BAH, S., \& LEHOHLA, P.J. 2005. Population Statistics. In: ZUBERI, T., SIBANDA, A., \& UDJO, E., (eds). The demography of South Africa. New York: M.E. Sharpe.

KHOSRAVI, A., RAO, C., NAGHAVI, M., TAYLOR, R., JAFARI, N., \& LOPEZ, A.D. 2008. Impact of misclassification on measures of cardiovascular disease mortality in the Islamic Republic of Iran: a cross-sectional study. Bulletin of the World Health Organisation, 86(9): 688-696.
LOZANO, F., NAGHAVI, M., FOREMAN, K. et al. 2012. Global and regional mortality from 235 causes of death from 20 age groups in 1990 and 2010: a systematic analysis for the global burden of disease study 2010. The LANCET, 380, 20952128.

MAINALI, K.P. 2006. Global Disease and Environmental Health. Frontiers in Ecology and the Environment, 4, 289.

MCKINNEy D. Youtube 2012: Health: Communicable diseases. [Online] Available: https://www.youtube.com/watch? v=oi5Yd_wBW 8g Accessed I5 October 2015.

MOSLEY, H. 1984. Child survival: research and policy. In: CHEN, W.H., \& CHEN, L.C. (ed). Child survival: strategies for research. Population and Development Review, A supplement to vol. 10, 1984, 3-24.

MOSLEY, H. \& CHEN, L.C. 1984. An analytical framework for the study of child survival in developing countries. In, CHEN, W.H., \& CHEN, L.C. (eds.). Child survival: strategies for research. Population and Development Review, A supplement to vol 10, 1984: 25-45.

NOTESTEIN, F.W. 1945. Population-the long view. In: SCHULTZ, T.W, (ed.). Food for the World. University of Chicago Press: Chicago.

Omran, A.R. 2005. "The epidemiologic transition: a theory of the epidemiology of population change". The Milbank Quarterly, 83, 73I-757.

PILLAY-VAN WYK, V., MSEMBURI, W., LAUBSCHER, R., \& DORRINGTON, R.E., et al. 2016. Mortality trends and differentials in South Africa, 1997-2012. Lancet Glob Health, 4(9):e64253. doi: 10.1016/S22।4-109X(16)301 I3-9.

RAMPATIGE, R., GAMAGE, S., PEIRIS, S., \& LOPEZ, A.D. 20/3. Assessing the reliability of causes of death reported by the vital registration system in Sri Lanka: medical records review in Colombo. Health Information Management Journal, 42(3), 20-28.

RUMAKOM, P., PRASARTKUL, P., GUEST, P., THONGTHAI, V., \& PUNPUING, S. 2002. Change to the epidemiological transition in Thailand due to HIV/AIDS: implications for population and health policies. Paper presented at the International Union for the Scientific Study of Population Regional Conference on Southeast Asia's Population in a Changing Asian Context, Bangkok, Thailand, June I0-13.

SALOMON, J.A., \& MURRAY, C.J.L. 2004. "The epidemiological transition revisited: compositional models for causes of death by age and sex". Population and Development Review, 28, 205228. 
SANDERS, J.W., FUHRER, G.S., JOHNSON, M.K., \& RIDDLE, M.S. 2008. The epidemiological transition: the current status of infectious diseases in the developed world versus the developing world. Science Progress, 9I, I-37.

STATISTICS SOUTH AFRICA. 1998. The people of South Africa: Population Census, 1996. Pretoria: Statistics South Africa.

STATISTICS SOUTH AFRICA. 20I2. Census 20II: Methodology and highlights of key results. Pretoria: Statistics South Africa.

STATISTICS SOUTH AFRICA. 20I4. Mortality and causes of death in South Africa, 2013: Findings from death notification. Pretoria: Statistics South Africa.

THE LANCET. 2012. Age-specific and sex-specific mortality in 187 countries, 1970-2010: a systematic analysis for the burden of disease study 2010. The Lancet, 380, 207I-94.

THE LANCET. 20I5. "Global, regional, and national age-sex specific all-cause and cause-specific mortality for 240 causes of death, 1990-2013: a systematic analysis for the global burden of disease study 20 I3". The Lancet, 385, I I 7-7I.

THE WORLD BANK. 20I3. The global burden of disease: main findings for sub-Saharan Africa, 2013. [Online] Available: http://www.worldbank.org/en/news/feature/20I3/ 09/09/global-burden-of-disease-findings-for-subsaharan-africa. Accessed 15 October 2015.

THOMPSON, W.S. 1929. Population. American Journal of Sociology, 34, 959-975.
UDJO, E.O. 2006. Estimation of mortality from vital registrations in South Africa. Current HIV Research, 4:469-474.

UDJO, E.O. 201I. The role of chronic noncommunicable diseases in mortlity rates in South Africa, 1997-2006. In: PHASWANA-MAFUYA, N., TASSIOPOULOU,D. (eds). Non-communicable diseases (NCDs) in developing countries. New York: Nova Science Publishers, Inc

UDJO, E.O., Lalthapersad-Pillay P. 20I4. Mortality from non-communicable diseases in South Africa, 1997-2009. African Population Studies: Supplement on Population Issues in South Africa, 28 (I): 610-622.

WAHDAN, M.H. 1996. The epidemiological transition. Eastern Mediterranean Health Journal, 2, 8-20.

WEEKS, J.R. 1999. Population: An introduction to concepts and issues. Belmont: Wadsworth Publishing Company.

WORLD HEALTH ORGANISATION. 2004. Global burden of disease 2004 Annex C: Analysis categories and mortality data sources. WHO: Geneva.

YANG, G., KONG, L., ZHAO, W. et al. 2008. Emergence of chronic non-communicable diseases in China. The LANCET, 378, I697-I 705.

YoUNG, F., CRITCHLEY, J., JOHNSTONE, L., \& UNWIN, N. 2010. Globalization and the dual disease burden in sub-Saharan Africa. Diabetes Voice, 55, 30-32. 